\title{
DAMPAK PEMBANGUNAN JALAN LINGKAR NIPAH TERHADAP KEGIATAN EKONOMI MASYARAKAT DI PANTAI AIR MANIS KOTA PADANG
}

\author{
Memo Memito ${ }^{1}$, Yurni Suasti ${ }^{2}$ \\ Program Studi Pendidikan Geografi, \\ Fakultas Ilmu Sosial, Universitas Negeri Padang \\ Emailmemolegumer@ymail.com
}

\begin{abstract}
ABSTRAK
Penelitian ini bertujuan untuk melihat komparasi jumlah aset dan pendapatan yang diperoleh pelaku ekonomi di Pantai Air Manis sebelum dan sesudah pembangunan Jalan Lingkar Nipah. Jenis penelitian deskriptif kuantitatif dengan subyek penelitian pelaku ekonomi. Data dianalisis menggunakan Paired Sample T-Test terhadap 133 pelaku ekonomi. Hasil penelitian menemukan terdapatnya peningkatan signifikan jumlah aset kelompok pelaku ekonomi pedagang makanan, jasa ATV, pedagang minuman, pedagang souvenir dan aksesories, dan sebaliknya tidak terjadinya peningkatan jumlah aset kelompok pedagang makanan minuman, pedagang pakaian dan penyedia jasa. Terdapatnya peningkatan pendapatan yang signifikan yang diperoleh semua kelompok pelaku ekonomi di Pantai Air Manis sebelum dan sesudah pembangunan Jalan Lingkar Nipah.
\end{abstract}

Kata Kunci: Pembangunan Jalan, Kegiatan Ekonomi, Pantai Air Manis

\section{ABSTRACT}

This research aims to look at the comparative amount of assets and income earned by economic actors in the Air Manis Beach before and after the construction of the Lingkar Nipah Road. Type of quantitative descriptive research with subjects of economic actors. The data were analyzed using Paired Sample T-Test on 133 economic actors. The research found a significant increase in the number of asset groups of food traders, ATV services, drink traders, souvenir and accessories traders, and conversely there was no increase in the number of assets of food and beverage merchants, clothing traders and service providers. There is a significant increase in the income earned by all groups of economic actors in Air Manis Beach before and after the construction of the Lingkar Nipah Road.

Keywords: Road Construction, Economic Activities, Air Manis Beach

\footnotetext{
${ }^{1}$ Mahasiswa Program Studi Pendidikan Geografi Untuk Wisuda September 2018

${ }^{2}$ Dosen Jurusan Geografi Fakultas Ilmu Sosial Unversitas Negeri Padang Dengan Dosen

Pembimbing Dra. Yurni Suasti M.Si
} 


\section{PENDAHULUAN}

Pantai Air Manis adalah sebuah pantai yang terletak di Kelurahan Air Manis, Kecamatan Padang Selatan, Kota Padang Sumatera Barat. Menurut sejarahnya pantai ini adalah sebuah pantai yang lekat dengan legenda Batu Malin Kundang. Pantai Air Manis merupakan salah satunya destinasi wisata yang menjadi primadona di Kota Padang. Pantai ini memiliki pasir yang berwarna coklat keputihputihan yang terhampar luas dan landai di sepanjang bibir pantai.

Pantai Air Manis sebelumnya hanya bisa diakses dari pusat Kota Padang melalui Jalan Koto Kaciak Kelurahan Mata Air Kecamatan Padang Selatan dengan kondisi jalan rusak ringan, lebar jalan yang sempit, penuh tanjakan dan penurunan tajam sepanjang $7 \mathrm{~km}$. Baru kemudian ada tahun 2015, Pemerintah Kota Padang melakukan program pelebaran dan pembukaan akses jalan baru menuju Pantai Air Manis. Jalan ini lebih dikenal dengan Jalan Lingkar Nipah, yang berawal dari Kaki Gunung Padang ke Air Manis dan berakhir di Teluk Bayur sepanjang 6,1 km dengan lebar jalan $6,3 \mathrm{~m}$. Untuk saat ini Jalan Lingkar Nipah yang sudah bisa digunakan adalah dari Kaki Gunung Padang menuju Pantai Air Manis dengan panjang jalan 2,7 km.

Pembukaan akses jalan baru ini, selain mempermudah akses rumah penduduk yang tinggal di sekitar Gunung Padang dan Jurnal Buana - Volume-2 No-5 2018
Kelurahan Air Manis, juga sekaligus sebagai sarana evakuasi bencana tsunami dan perkembangan objek wisata Pantai Air Manis. Pembangunan jalan ini juga berdampak terhadap peningkatan jumlah wisatawan yang berkunjung ke Pantai Air Manis.

Berdasarkan data dari Dinas Pariwisata dan Kebudayaan Kota Padang diketahui bahwa jumlah wisatawan yang berkunjung ke Pantai Air Manis pada tahun 2015 adalah 14.067 orang. Kemudian pada tahun 2016 naik menjadi 206.800 orang. Jumlah ini mengalami penurunan pada tahun 2017 menjadi 23.200 orang, hal ini terjadi karena adanya proses pengaspalan jalan tersebut sehingga menutup akses Jalan Lingkar Nipah ke Pantai Air Manis. Jalan ini baru diresmikan pada tanggal 31 desember 2017, sehingga tercatat bahwa jumlah wisatawan yang berkunjung pada tahun 2018 periode Januari- Juni naik secara drastis menjadi 228.492 orang (Dinas Pariwisata dan Kebudayaan Kota Padang 2018)

Menurut Gee (1989) dalam bukunya yang berjudul "The Travels Industry" bahwa "as tourism grows and travelers increases, so does the potential for both positive and negative impacts " yang berarti bahwa semakin meningkatnya pertumbuhan pariwisata dan wisatawan akan menimbulkan dampak positif dan negatif. Mathieson dan Wall (1982) juga 
mengatakan bahwa dimensi pariwisata di seluruh dunia memiliki pengaruh secara ekonomi, sosial, budaya dan lingkungan pada daya tarik wisata dan pengaruhnya bisa positif ataupun negatif. Dampak positif tersebut adalah terhadap peningkatan kegiatan ekonomi masyarakat di Pantai Air Manis baik dari segi aset maupun pendapatan.

Menurut Siregar (2004) aset secara umum adalah barang atau sesuatu barang yang mempunyai nilai ekonomi, nilai komersial, atau nilai tukar yang dimiliki oleh badan usaha, instansi atau individu perorangan. Aset adalah barang yang dalam pengertian hukum disebut benda yang terdiri dari benda tidak bergerak (tanah/bangunan) dan bergerak, baik yang berwujud maupun yang tidak berwujud yang tercangkup dalam aktiva/kekayaan suatu perusahaan

Sementara pendapatan dapat diartikan sebagai sumber utama dalam berbagai kegiatan ekonomi yang dilakukan oleh masyarakat. Semua kebutuhan akan barang dan jasa dapat terpenuhi dengan adanya pendapatan. Semakin tinggi tingkat pendapatan rumah tangga, maka semakin banyak kebutuhan rumah tangga tersebut dapat dipenuhi (Sukirno 2003).

Untuk melihat lebih jauh dampak pembangunan Jalan Lingkar Nipah terhadap kegiatan ekonomi masyarakat di Pantai Air Manis, maka perlu diwujudkan dalam sebuah penelitian.

\section{METODE PENELITIAN}

Jenis penelitian ini adalah deskriptif kuantitatif yang dilakukan di Pantai Air Manis Kota Padang

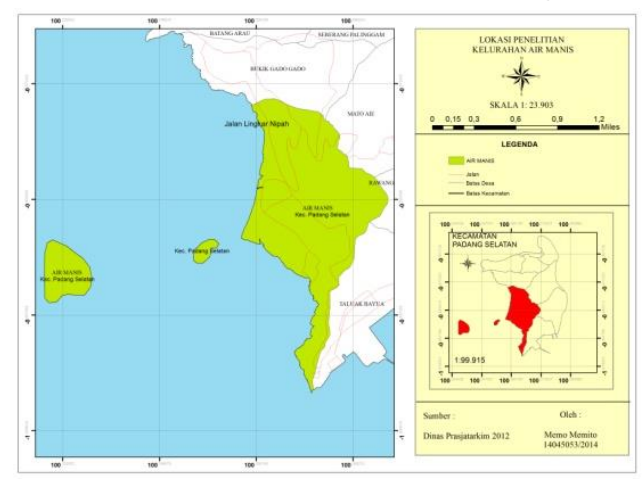

Gambar 1. Peta lokasi penelitian

Populasi dalam penelitian ini adalah seluruh pelaku ekonomi di Pantai Air Manis yang berjumlah 133 orang. Teknik pengambilan sampel dilakukan secara total sampling.

Data dikumpulkan melalui wawancara menggunakan kuesioner. Teknik analisis data yang digunakan adalah paired sample T-Test. 
Tabel 1. Sampel Pelaku Ekonomi di Kelurahan Air Manis Kecamatan Padang Selatan

\begin{tabular}{llc}
\multicolumn{2}{c}{ Kota Padang } \\
\hline No & Pelaku ekonomi & $\begin{array}{c}\text { Populasi } \\
\text { dan Sampel }\end{array}$ \\
\hline 1 & Pedagang Makanan dan Minuman & 38 \\
\hline 2 & Pedagang Makanan & 12 \\
\hline 3 & Pedagang Minuman & 14 \\
\hline 4 & Pedagang Aksesories dan Souvenir & 11 \\
\hline 5 & Penyedia Jasa (Jasa Toilet, Jasa Pondok dan Jasa Parkir) & 22 \\
\hline 6 & Jasa ATV & 15 \\
\hline 7 & Pedagang Pakaian & 21 \\
\hline Jumlah & 133
\end{tabular}

Sumber : Peneliti (2018)

\section{HASIL PENELITIAN DAN} PEMBAHASAN

Berdasarkan hasil penelitan dan pengolahan data yang dilakukan dapat diuraikan kegiatan ekonomi masyarakat pelaku ekonomi di Pantai Air Manis meliputi jumlah aset dan pendapatan.

\section{Asset}

Tabel 2. Jumlah Aset Pelaku Ekonomi Pantai Air Manis

\begin{tabular}{|c|c|c|c|c|c|}
\hline \multirow{2}{*}{ No } & \multicolumn{2}{|c|}{ Jumlah aset (Rp) } & \multirow{2}{*}{$\begin{array}{c}\text { Peningkatan } \\
\text { aset } \\
(\%) \\
\end{array}$} & \multirow{2}{*}{$\begin{array}{l}\text { Jumlah } \\
\text { responden }\end{array}$} & \multirow{2}{*}{$\%$} \\
\hline & Sebelum & Sesudah & & & \\
\hline 1 & $0-10.00 .000$ & $0-15.000 .000$ & $0-25 \%$ & 94 & $71 \%$ \\
\hline 2 & $11.00 .000-20.000 .000$ & $16.000 .000-30.000 .000$ & $26-50 \%$ & 16 & $12 \%$ \\
\hline 3 & $21.000 .000-30.000 .000$ & $31.000 .000-45.000 .000$ & $51-75 \%$ & 3 & $2 \%$ \\
\hline 4 & $31.000 .000-40.000 .000$ & $46.000 .000-60.000 .000$ & $76-100 \%$ & 20 & $15 \%$ \\
\hline 5 & $>40.000 .000$ & $>60.000 .000$ & Jumlah & 133 & $100 \%$ \\
\hline
\end{tabular}

Sumber : Olahan Data Primer (2018)

Data tabel 2 memperlihatkan bahwa, peningkatan jumlah aset pelaku ekonomi di Pantai Air Manis berkisar antara 5-20 juta dari sebelum adanya Jalan Lingkar Nipah. Secara umum peningkatan aset terbanyak terdapat pada peningkatan aset $0-25 \%$ yaitu $71 \%$ dari 133 jumlah pelaku ekonomi.
Kemudian peningkatan aset 76$100 \%$ sebanyak $15 \%$ dari 133 jumlah pelaku ekonomi dan peningkatan aset $26-50 \%$ sebanyak 12\%dari 133 jumlah pelaku ekonomi di Pantai Air Manis. Untuk lebih jelasnya dampak pembangunan Jalan Lingkar Nipah terhadap jumlah aset kelompok 
pelaku ekonomi dapat diuraikan

pada tabel 3 berikut:

Tabel 3. Hasil Perhitungan T-Test Jumlah Aset Pelaku Ekonomi Sebelum dan Sesudah Pembangunan Jalan Lingkar Nipah

\begin{tabular}{llccc}
\hline No & \multicolumn{1}{c}{ Pelaku Ekonomi } & Responden & $\begin{array}{c}\text { Hasil Paired } \\
\text { Sample T- } \\
\text { Test }\end{array}$ & Keterangan \\
\hline 1 & $\begin{array}{l}\text { Pedagang } \\
\text { Minuman }\end{array}$ & 28 & 0,199 & $\mathrm{H}_{0}$ diterima \\
\hline 2 & Pedagang Makanan & 12 & 0,028 & $\mathrm{H}_{1}$ diterima \\
\hline 3 & Pedagang Pakaian & 21 & 0,148 & $\mathrm{H}_{0}$ diterima \\
\hline 4 & Penyedia Jasa & 22 & 0,653 & $\mathrm{H}_{0}$ diterima \\
\hline 5 & Jasa ATV & 15 & 0,011 & $\mathrm{H}_{1}$ diterima \\
\hline 6 & Pedagang Minuman & 14 & 0,049 & $\mathrm{H}_{1}$ diterima \\
\hline 7 & $\begin{array}{l}\text { Pedagang Aksesories } \\
\text { dan Souvenir }\end{array}$ & 11 & 0,005 & $\mathrm{H}_{1}$ diterima \\
\hline
\end{tabular}

Sumber : Olahan Data Primer 2018

Data tabel 3 memperlihatkan bahwa, jumlah aset pelaku ekonomi yang mengalami peningkatan terjadi pada kelompok pedagang makanan, jasa ATV, pedagang minuman, pedagang souvenir dan aksesories, dan sebaliknya tidak mengalami peningkatan pada kelompok pedagang makanan minuman, pedagang pakaian dan penyedia jasa sebelum dan sesudah pembangunan Jalan Lingkar Nipah, dan peningkatan jumlah aset tertinggi terjadi pada kelompok pedagang aksesories dan souvenir.

\section{Pendapatan}

Tabel 4 .Pendapatan Pelaku Ekonomi

\begin{tabular}{|c|c|c|c|c|c|}
\hline \multirow{2}{*}{ No } & \multicolumn{2}{|c|}{ Jumlah pendapatan (Rp) } & \multirow{2}{*}{$\begin{array}{c}\text { Peningkatan } \\
\text { pendapatan } \\
(\%)\end{array}$} & \multirow{2}{*}{$\begin{array}{l}\text { Jumlah } \\
\text { responden }\end{array}$} & \multirow{2}{*}{$\%$} \\
\hline & Sebelum & Sesudah & & & \\
\hline 1 & $0-800.000$ & $0-3.000 .000$ & $0-25 \%$ & 14 & $11 \%$ \\
\hline 2 & $900.000-1.600 .000$ & $3.100 .000-6.000 .000$ & $26-50 \%$ & 22 & $16 \%$ \\
\hline 3 & $1.700 .000-2.400 .000$ & $6.100 .000-9.000 .000$ & $51-75 \%$ & 20 & $15 \%$ \\
\hline 4 & $2.500 .000-3.200 .000$ & $9.100 .000-12.000 .000$ & $76-100 \%$ & 77 & $58 \%$ \\
\hline 5 & $3.300 .000-4.000 .000$ & $12.100 .000-15.000 .000$ & Jumlah & 133 & $100 \%$ \\
\hline
\end{tabular}

Sumber : Olahan Data Primer (2018)

Data tabel 4 memperlihatkan bahwa, peningkatan pendapatan pelaku ekonomi di Pantai Air Manis berkisar antara 1,2-11 juta dari sebelum adanya Jalan Lingkar
Nipah. Secara umum peningkatan pendapatan terbanyak terdapat pada peningkatan $76-100 \%$ yaitu $58 \%$ dari 133 jumlah pelaku ekonomi. Kemudian peningkatan pendapatan 
$26-50 \%$ sebanyak $16 \%$ dari 133 jumlah pelaku ekonomi dan peningkatan $51-75 \%$ sebanyak $15 \%$ dari jumlah pelaku ekonomi di Pantai Air Manis. Untuk melihat lebih jauh dampak pembangunan Jalan Lingkar Nipah terhadap pendapatan kelompok pelaku ekonomi dapat diuraikan pada tabel 5 berikut:

Tabel 5. Hasil Perhitungan T-Test Pendapatan Pelaku Ekonomi Sebelum dan

\begin{tabular}{llccc}
\multicolumn{4}{c}{ Sesudah Pembangunan Jalan Lingkar Nipah } \\
\hline No & Pelaku Ekonomi & Responden & $\begin{array}{c}\text { Hasil Paired } \\
\text { Sample T- } \\
\text { Test }\end{array}$ & Keterangan \\
\hline 1 & $\begin{array}{l}\text { Pedagang Makanan } \\
\text { Minuman }\end{array}$ & 28 & 0,000 & $\mathrm{H}_{1}$ diterima \\
\hline 2 & Pedagang Makanan & 12 & 0,008 & $\mathrm{H}_{1}$ diterima \\
\hline 3 & Pedagang Pakaian & 21 & 0,000 & $\mathrm{H}_{1}$ diterima \\
\hline 4 & Penyedia Jasa & 22 & 0,027 & $\mathrm{H}_{1}$ diterima \\
\hline 5 & Jasa ATV & 15 & 0,006 & $\mathrm{H}_{1}$ diterima \\
\hline 6 & Pedagang Minuman & 14 & 0,002 & $\mathrm{H}_{1}$ diterima \\
\hline 7 & $\begin{array}{l}\text { Pedagang Aksesories } \\
\text { dan Souvenir }\end{array}$ & 11 & 0,002 & $\mathrm{H}_{1}$ diterima \\
\hline
\end{tabular}

\section{Sumber : Olahan Data Primer 2018}

Data tabel 5 memperlihatkan bahwa, terdapatnya peningkatan pendapatan pada semua kelompok pelaku ekonomi sebelum dan sesudah pembangunan Jalan Lingkar Nipah, dan peningkatan tertinggi terjadi pada kelompok pedagang makanan minuman, dan pedagang pakaian.

\section{PENUTUP}

\section{Kesimpulan}

Penelitian ini dapat disimpulkan bahwa kegiatan ekonomi masyarakat yang mengalami peningkatan jumlah aset terjadi pada kelompok pelaku ekonomi pedagang makanan, jasa ATV, pedagang minuman, pedagang souvenir dan aksesories, dan sebaliknya tidak mengalami peningkatan pada kelompok pedagang makanan minuman, pedagang pakaian dan penyedia jasa sebelum dan sesudah pembangunan Jalan Lingkar Nipah

Dari segi pendapatan, terdapatnya peningkatan pendapatan pada semua kelompok pelaku ekonomi sebelum dan sesudah pembangunan Jalan Lingkar Nipah.

\section{Saran}

Peneliti menyarankan pemerintah Kota Padang hendaknya melakukan pelebaran dan rehabilitasi akses Jalan Koto 
Kaciak ke Air Manis dan melakukan pemeliharaan Jalan Lingkar Nipah dan Jalan Koto Kaciak agar selalu mulus yang memudahkan wisawatan mengakses jalan menuju Pantai Air Manis.

Bagi masyarakat pelaku ekonomi di Pantai Air Manis, baik yang berasal dari Kelurahan Air Manis maupun kelurahan lain, agar teru dapat meningkatkan kegiatan ekonominya dalam menyediakan berbagai kebutuhan wisawatan dan turut serta dalam melakukan pengembangan dan pemeliharaan jalan serta objek wisata Pantai Air Manis bersama Pemerintah.

\section{DAFTARP USTAKA}

Dinas Pariwisata dan

Kebudayaan Kota Padang 2018.

Gee, Chuky.Y. 1989. The Travel Industry. New York: Van Nostrand Reinhold.

Mathienson, A, And Wall,G. 1982.

Tourism: Economic, Physical And Social Impacts. Harlow: Longman. Siregar, D. D. 2004. Manajemen Aset. Strategi Penataan Konsep Pembangunan Berkelanjutan Secara Nasional Dalam Konteks Kepala Daerah Sebagai Ceo'sPada Era Globalisasi dan Otonomi Daerah. PT. Gramedia Pustaka Utama.
Sukirno, Sadono. 2008. Makro Ekonomi, Teori Pengantar. Penerbit PT. Rajagrafindo Persada, Jakarta. 